\title{
A study to assess the effectiveness of laughter therapy and Nurse Led Intervention on physical and psychosocial problems among institutionalized elderly with BADL deficit at Ernakulam District in Kerala
}

\author{
Soney M. Varghese \\ College of Nursing, Gulf Medical University, Ajman, United Arab Emirates
}

\section{A R T I C L E I N F O}

\section{Keywords:}

Physical and psychosocial problems

BADL Deficit

Institutionalized elderly

\begin{abstract}
A B S T R A C T
Introduction: A longer life brings with it opportunities, not only for older people and their families, but also for societies as a whole. Yet the extent of these opportunities and contributions depends heavily on one factor health. ${ }^{1}$

Methodology: A quantitative approach with an experimental design was adopted with an aim to assess the effectiveness of laughter therapy, Nurse led interventions and combined interventions on physical, psychosocial problems and BADL deficits among elderly. Tools were developed by the researcher and were validated. The reliability of the tool was 0.93 . Old age homes were selected by convenience sampling and selected old age homes were randomly assigned for interventional and control groups. Groups divided as control, laughter therapy, Nurse led intervention and combined interventional group. Post test was conducted on eighth week. The obtained data were analyzed using SPSS software.

Results: From the results it had been concluded that laughter therapy and Nurse Led Intervention were effective but combined intervention is more effective.

Discussion: The study brought out the findings that there is a significant difference in the BADL deficit, physical and psychosocial problems between the elderly who receive laughter therapy, Nurse Led Intervention and combined intervention.

Conclusion: A comprehensive public health response must address this wide range of older people's experiences and needs. Health systems need to be better organized around older people's needs and preferences, designed to enhance older peoples intrinsic capacity, and integrated across settings and care providers.
\end{abstract}

\section{Introduction}

Old age is an inevitable part of the healthy human life and in many ways charming too. Ageing is a biological process and not a disease. During this biological process significant changes occur in the human body. Prevention of disability and loneliness can help elderly to live happy and longer life. Most illnesses today are stress related and chronic stress attacks the old age. ${ }^{1}$ Physical health does decline with age, this does not mean that older adults are incapacitated. Disability is usually defined in terms of restrictions in the ability to perform activities of daily living or the inability to function independently in terms of basic ADL. ${ }^{2}$

Rakesh, Babita, Beulah and Varidmala ${ }^{3}$ stated that with an increasing population ageing and by the changing context of the world, elderly has been pushed into a state of loneliness, helplessness frustration and meaningless life leading them to various psychosocial problems. The psychosocial problems were greater in institutionalized elderly. They expressed the need of encouragement towards group activities. Older adults should be trained for active ageing.

As people age, their self-care ability is weakened by one or more functional limitations; this can result in admission to a long-term care institutions such as a nursing home. Residents may become more dependent on caregivers if the caregivers perform the activities for them, rather than allowing the residents to do for themselves (Fuller, Yu, Jeter, Gralink and Minkler, 2000).

Research evidence also indicated that having severe pain or psychosocial problems are significant source of inactivity. Because of these reasons an older may lie in bed or set in wheel chair for the whole day which further aggravates the disability. ${ }^{4}$

E-mail address: dr.soney@gmu.ac.ae. 


\section{Methods}

In this study, quantitative approach was adopted using an experimental design. Random assignment was used to allot the group to different intervention. Institutionalized elderly male and female in the age group of 60-85 years with Basic Activities of Daily Living (BADL) deficit and having physical and psychosocial problems were selected, based on the inclusion criteria. They were divided into four groups having a sample of size 50 was taken for each group.

Group A: (control group) received no intervention only social visit.

Group B: received laughter therapy alone.

Group C: received Nurse Led Intervention alone.

Group D: received both Nurse Led Intervention and laughter therapy.

$$
\text { Sample size } \left.\mathrm{n}=(\mathrm{z} \text { value })^{2} \mathrm{x} \text { (S.D. }\right) 2 / \mathrm{d}^{2}
$$

$=(1.96)^{2} \times 6.5 /\{1.8)^{2}=50.1$.

$=50$ approx.

Who is completely paralyzed, bed bound for more than 6 months having severe physical and psychosocial problems were excluded from the study.

The tools used were Tool 1: Demographic proforma, Tool 2: BADL assessment tool to assess the activities of Daily living If the residents can perform any of these task independently mark ' 0 ' dependent marked as ' 1 '. For each task one mark is given and the maximum score is 10 . Tool 3: Checklist to identify the physical problems among elderly. Each items had three options like Always (Score 2) Sometimes -(Score 1)Never -(Score 0 ). Totally there were 42 items with maximum score of 84 and minimum score of 0 . Tool 4:Structured questionnaire to assess the Psychosocial problems. using 3 point rating scale with 33 items. So the maximum score is 66 and the minimum score is 0 The content validity of the tools were obtained by submitting the tools to experts in the field of medicine and nursing. Tools were translated to Malayalam and retranslated to English by a language expert. Structured interview schedule was used to collect the data. Pretesting of the tools were done by administering the tools to 20 elderly to determine the clarity of the items, presence of ambiguous terms, time required and the feasibility of the tools. Tools were administered to 20 elderly to determine the reliability by test-retest method. The reliability co-efficient ( $r$ ) value of tools were 0.92 (tool 2), 0.96 (tool 3), and 0.88 (tool 4) respectively. Pilot study data was conducted to assess the feasibility of the tools, to determine any flaws in the study design and to decide plan for main data analysis. Main data collection was done among 200 elderly.

\section{Ethical considerations}

The research proposal was approved by the Research Committee of Rajah Muthiah Medical College, Annamalai University. The study has been approved by the ethical committee of Malankara Orthodox Syrian Christian Medical College Hospital, Kolanchery, Ernakulam, Kerala, India. Permission was obtained from the concerned authorities of selected old age homes.

\section{Data collection procedure}

Phase I: Screening potential subjects and dividing them into sub group (one week).

Researcher explained about the study to the care takers. Based on the information's obtained from the care takers and by using Assessment tools screened the institutionalized elderly who are physically able to perform basic activities of daily living like feeding, washing, dressing and grooming and dependent on care takers for the same with physical and psychosocial problems. The selected subjects were grouped into 4 groups based on their location (old age homes). Then they were randomly allotted to 4 groups.

Phase II:The pretest was done to assess their BADL deficit level, physical and psychosocial problems.
Phase III: Implementation of intervention.

$>$ Implemented the selected intervention.

> Researcher ensured that subjects will continue to practice and develop their skills in managing themselves after the completion of the session.

- Each session took about thirty to $40 \mathrm{~min}$ for each group.

Phase IV: Assessed the effect of the intervention in terms of improvement in the BADL activities, physical and psychosocial problems using the same interview schedule. Posttest was done on 8th week.

Group A: Control Group: Data collection was started with the control group. Pretest was done for samples. Social visits were conducted every week and on 8th week posttest was conducted.

Group B: Laughter therapy: Pretest was conducted for the experimental group B and then the group was divided into three sub groups. Each of these three groups were again divided into another two groups for the effective administration of laughter therapy. The laughter therapy was administered in the morning and in the evening sessions in two consecutive days and weekly once follow up was done and on 8th week posttest was conducted. Provision was made to play the $\mathrm{CD}$ on laughter therapy daily at specified times in the morning and evening. Laughter therapy video was played every day morning and in the evening. Institutionalized elderly were asked to practice it in the morning and evening on daily basis and supervised by the care takers and the care takers were reminded by the researcher over the phone.

Training scheduled.

\begin{tabular}{lll}
\hline Group B & Demonstration of laughter therapy & Day \\
\hline Sub Group 1 & $1-8$ & Monday and Tuesday \\
& $9-16$ & \\
Sub Group 2 & $17-24$ & Wednesday and Thursday \\
& $25-33$ & \\
Sub Group 3 & $34-41$ & Friday and Saturday \\
& $42-50$ & \\
\hline
\end{tabular}

Group C: Nurse Led Intervention Group.

After completing posttest for Group B, pretest was conducted for group $C$ and they were also grouped. For each sub-group Nurse Led Intervention was administered in two session in the morning and in the evening and advised them to follow the instructions and on weekly basis follow up also done, Two days training was given for each group. Weekly follow up was done and on 8th week posttest was conducted. The care takers were informed to encourage the elderly to do BADL activities on their own.

Training schedule.

\begin{tabular}{cll}
\hline Group C & $\begin{array}{l}\text { Demonstrations of Nurse Led } \\
\text { Intervention }\end{array}$ & Day \\
\hline Sub Group & $1-8$ & Monday and Tuesday \\
1 & $9-16$ & \\
Sub Group & $17-24$ & Wednesday and \\
2 & $25-33$ & Thursday \\
Sub Group & $34-41$ & Friday and Saturday \\
3 & $42-50$ & \\
\hline
\end{tabular}

Group D: Combined Intervention (Nurse Led Intervention and Laughter Therapy.

After completing posttest for group C, pretest was conducted for group D and same like other groups they were also divided into sub groups. For each sub-group laughter therapy and Nurse Led Intervention were applied in two sessions in the morning and in the evening. After giving training for two days, weekly follow up was done. Elderly were asked to practice it in the morning and evening on daily basis and supervised by the care takers and the care takers were reminded by the researcher over the phone. Provision was made to play the $C D$ on 
laughter therapy daily at specified time morning and evening. They were encouraged to do BADL activates and practice the advices given in structured teaching programme. A booklet on management of physical and psychosocial problems was given for their reference. On $8^{\text {th }}$ week posttest was conducted.

\begin{tabular}{cll}
\hline Group D & $\begin{array}{l}\text { Demonstration of Nurse Led Intervention and } \\
\text { laughter therapy }\end{array}$ & Day \\
\hline Sub Group & $1-8$ & Monday and \\
1 & $9-16$ & Tuesday \\
Sub Group & $17-24$ & Wednesday and \\
2 & $25-33$ & Thursday \\
Sub Group & $34-41$ & Friday and Saturday \\
3 & $42-50$ & \\
\hline
\end{tabular}

For administering laughter therapy it took $30-40 \mathrm{~min}$. For structured teaching programme $30-45 \mathrm{~min}$ and Nurse Led Intervention took around $1 \mathrm{~h}$ to complete.

\section{Plan for data analysis}

The data analysis plan included both descriptive and inferential statistics frequency and percentage distribution. Means and standard deviation was used to identify the BADL deficit, physical and psychosocial problems. Chi-square test was used to correlate the BADL deficit, physical, psychosocial problems with selected socio-demographic variables. Paired ' $t$ ' test was used to evaluate the effectiveness of laughter therapy, Nurse Led Intervention and combined intervention on BADL deficit, physical and psychosocial problems. ANOVA (L.S.D. multiple) was used for comparison of BADL deficit, physical and psychosocial problems in all the four groups after intervention. ANCOVA (Bonferroni multiple comparison) was used for the comparison of posttest mean scores by controlling significant demographic variables.

\section{Results}

\subsection{Section 1: Description of sample characteristics}

As shown in Table 1, majority (42-44\%) of the institutionalized elderly persons was between 60 and 70 years, majority (54-56\%) of the institutionalized elderly persons was male. In all the four groups majority $(52-56 \%)$ could only read and write. Very few (6-14\%) had completed 8-10 years of schooling in all the four groups. Regarding income $48 \%-54 \%$ of the institutionalized elderly in all the four groups had no income and $26 \%$ of $30 \%$ had Rs. $2000 /$ - as income in all the four groups. Regarding marital status, $40-46 \%$ were unmarried, $50 \%-56 \%$ were widow and widowers and only $4 \%$ were divorced in all the four groups.

As shown in Table 2, Regarding physical health status, $62-66 \%$ had complaints of one or the other physical health problem. Majority of institutionalized elderly (98\%) were staying for less than a year and 1-3 years in all the four groups. The non significant ' $P$ ' value inferred that the institutionalized elderly persons were similar by duration of stay in old age homes. In all the four groups majority ( $66 \%, 74 \%, 72 \% \& 70 \%)$ of them came to old age home due to lack of care by family members. And $26 \%-34 \%$ came to old age home due to conflicting relationship with family. A chi-square test had been applied to find out the difference in the reason for institutionalization in all the four groups. The non significant ' $\mathrm{P}$ ' value inferred that the institutionalized elderly persons were similar in terms of reason for institutionalization.

\subsection{Section 2: Description of BADL deficit among institutionalized elderly in all four groups}

As per Table 3, Majority of the institutionalized elderly were able to use the napkins and put on chappals. The prevalence of BADL deficit among the institutionalized elderly were more in putting on dress (95\%), Tooth brushing (96\%), using spoon or hand for eating (90\%), Drinking from glass (75\%), combing hair (38\%), and less in face and hand washing (10\%) and putting on chappals (8\%). A chi square test had been applied and the non significant ' $\mathrm{P}$ ' value inferred that the level of BADL deficit had been similar in all the four groups before intervention.

\subsection{Section 3: Description of physical problems among institutionalized elderly in all four groups in pretest}

As per Table 4 the average score on muscular skeletal system problem was found to be 5.12, 5.16, 5.18 and 5.20 respectively for the group A, B, C, D respectively. The average score on central nervous system

Table 1

Frequency and Percentage Distribution of Selected Demographic Variables of Institutionalized elderly in Control and Experimental Groups (n $==200$ ).

\begin{tabular}{|c|c|c|c|c|c|c|c|c|c|c|c|}
\hline \multirow[t]{2}{*}{ Sl. No. } & \multirow[t]{2}{*}{ Demographic Variables } & \multicolumn{2}{|c|}{ Group A $(n=50)$} & \multicolumn{2}{|c|}{ Group B $(n=50)$} & \multicolumn{2}{|c|}{ Group C $(n=50)$} & \multicolumn{2}{|c|}{ Group D $(n=50)$} & \multirow[t]{2}{*}{ Chi Square } & \multirow[t]{2}{*}{ Level of Significance } \\
\hline & & No. & $\%$ & No. & & No. & $\%$ & No. & $\%$ & & \\
\hline \multirow[t]{5}{*}{1.} & Age (in years) & & & & & & & & & & \\
\hline & a) $60-65$ & 16 & 32 & 16 & 32 & 18 & 36 & 17 & 34 & 0.411 & 1.000 \\
\hline & b) $66-70$ & 22 & 44 & 22 & 44 & 21 & 42 & 21 & 42 & & \\
\hline & c) $71-75$ & 08 & 16 & 08 & 16 & 08 & 16 & 08 & 16 & & \\
\hline & d) $76-80$ & 04 & 08 & 04 & 08 & 03 & 06 & 04 & 08 & & \\
\hline \multirow[t]{3}{*}{2.} & Gender & & & & & & & & & & \\
\hline & a) Male & 27 & 54 & 28 & 56 & 28 & 56 & 27 & 54 & 0.081 & 0.999 \\
\hline & b) Female & 23 & 46 & 22 & 44 & 22 & 44 & 23 & 46 & & \\
\hline \multirow[t]{5}{*}{3.} & Educational Status & & & & & & & & & & \\
\hline & a) Can read and write & 28 & 56 & 25 & 50 & 27 & 54 & 26 & 52 & 0.807 & 1.000 \\
\hline & b) $<7$ years of schooling & 15 & 30 & 13 & 26 & 17 & 34 & 16 & 32 & & \\
\hline & c) 8-10 years of schooling & 04 & 08 & 07 & 14 & 03 & 06 & 03 & 06 & & \\
\hline & d) 11-12 years of schooling & 03 & 06 & 05 & 10 & 03 & 06 & 05 & 10 & & \\
\hline \multirow[t]{4}{*}{4.} & Monthly income in rupees & & & & & & & & & & \\
\hline & a) No income & 25 & 50 & 24 & 48 & 26 & 52 & 27 & 54 & 0.389 & 0.999 \\
\hline & b) Upto Rs. 2000 & 13 & 26 & 15 & 30 & 13 & 26 & 15 & 30 & & \\
\hline & c) Rs. $2001-5000$ & 12 & 24 & 11 & 22 & 11 & 22 & 08 & 16 & & \\
\hline \multirow[t]{5}{*}{5.} & Marital Status & & & & & & & & & & \\
\hline & a) Married living together & 0 & 0 & 0 & 0 & 0 & 0 & 0 & 0 & 1.360 & 0.999 \\
\hline & b) Unmarried & 23 & 46 & 22 & 44 & 23 & 46 & 20 & 40 & & \\
\hline & c) Widow/Widower & 25 & 50 & 26 & 52 & 25 & 50 & 28 & 56 & & \\
\hline & d) Divorced & 02 & 04 & 02 & 04 & 02 & 04 & 02 & 04 & & \\
\hline
\end{tabular}

Group A-Control Group B - Laughter Therapy.

Group C -Nurse Led Intervention Group D - Combined Intervention. 
Table - 2

Frequency and percentage distribution of selected demographic variables of institutionalized elderly in control and experimental groups (n $=200$ ).

\begin{tabular}{|c|c|c|c|c|c|c|c|c|c|c|c|}
\hline \multirow{2}{*}{$\begin{array}{l}\text { Sl. } \\
\text { No. }\end{array}$} & \multirow[t]{2}{*}{ Demographic Variables } & \multicolumn{2}{|c|}{ Group A $(n=50)$} & \multicolumn{2}{|c|}{ Group B $(n=50)$} & \multicolumn{2}{|c|}{ Group C $(\mathrm{n}=50)$} & \multicolumn{2}{|c|}{ Group D $(n=50)$} & \multirow[t]{2}{*}{ Chi Square } & \multirow[t]{2}{*}{ Level of Significance } \\
\hline & & No. & $\%$ & No. & $\%$ & No. & $\%$ & No. & $\%$ & & \\
\hline \multirow[t]{11}{*}{1.} & Physical Health Status & & & & & & & & & & \\
\hline & a) History of long term illness & 33 & 66 & 31 & 62 & 31 & 62 & 32 & 64 & 0.237 & 0.971 \\
\hline & a) Present & & & & & & & & & & \\
\hline & b) Absent & 17 & 34 & 19 & 38 & 19 & 38 & 18 & 36 & & \\
\hline & b) If present mention the disease & & & & & & & & & - & - \\
\hline & - Hypertension & 14 & 28 & 16 & 32 & 9 & 18 & 11 & 22 & & \\
\hline & - Respiratory & 9 & 18 & 10 & 20 & 13 & 26 & 15 & 30 & & \\
\hline & Disease & & & & & & & & & & \\
\hline & - Diabetes & 4 & 8 & 5 & 10 & 6 & 12 & 4 & 8 & & \\
\hline & Mellitus & & & & & & & & & & \\
\hline & - Arthritis & 6 & 12 & 0 & 0 & 3 & 6 & 2 & 4 & & \\
\hline \multirow[t]{4}{*}{2.} & Duration of Stay in Old Age House & & & & & & & & & & \\
\hline & a) Less than one year & 28 & 56 & 23 & 46 & 26 & 52 & 26 & 52 & 0.552 & 0.999 \\
\hline & b) $1-3$ years & 21 & 42 & 26 & 52 & 23 & 46 & 23 & 46 & & \\
\hline & c) $3-5$ years & 01 & 02 & 01 & 02 & 01 & 02 & 01 & 02 & & \\
\hline \multirow[t]{4}{*}{3.} & Reason for Institutionalization & & & & & & & & & & \\
\hline & a) Lack of care by family members & 33 & 66 & 37 & 74 & 36 & 72 & 35 & 70 & 0.252 & 0.974 \\
\hline & b) Conflicting relationship with family & 17 & 34 & 13 & 26 & 14 & 28 & 15 & 30 & & \\
\hline & c) Problem of accommodating at home & 0 & 0 & 0 & 0 & 0 & 0 & 0 & 0 & & \\
\hline
\end{tabular}

Group A-Control Group B - Laughter Therapy.

Group C -Nurse Led Intervention Group D -Combined intervention group - Combined Intervention.

Table 3

Mean and standard deviation of BADL deficit before intervention $(\mathrm{n}=200)$.

\begin{tabular}{lllll}
\hline Groups & Mean & $\begin{array}{l}\text { Standard } \\
\text { Deviation }\end{array}$ & $\begin{array}{l}\text { ANOVA 'F' } \\
\text { Value }\end{array}$ & P Value \\
\hline Control & 5.48 & 0.677 & 0.882 & 0.45 \\
Laughter therapy & 5.46 & 0.705 & & (S) \\
$\begin{array}{l}\text { Nurse Led } \\
\quad \text { Intervention }\end{array}$ & 5.34 & 0.745 & & \\
$\begin{array}{l}\text { Combined } \\
\text { intervention }\end{array}$ & 5.28 & 0.757 & & \\
\hline
\end{tabular}

Table 4

Mean and standard deviation of physical problems before intervention $(\mathrm{n}=$ 200).

\begin{tabular}{lllll}
\hline Groups & Mean & $\begin{array}{l}\text { Standard } \\
\text { Deviation }\end{array}$ & $\begin{array}{l}\text { ANOVA 'F' } \\
\text { Value }\end{array}$ & P Value \\
\hline Control & 49.88 & 8.08 & 0.012 & 0.998 \\
Laughter therapy & 50.04 & 8.08 & & (NS) \\
$\begin{array}{c}\text { Nurse Led } \\
\quad \text { Intervention }\end{array}$ & 50.08 & 8.05 & & \\
$\begin{array}{c}\text { Combined } \\
\text { intervention }\end{array}$ & 50.18 & 8.155 & & \\
\hline
\end{tabular}

problems was found to be 1.74 in all the four groups. The average score on respiratory system physical problems were 4.8, 4.82, 4.84, 4.86 respectively in groups $\mathrm{A}, \mathrm{B}, \mathrm{C}$ and $\mathrm{D}$ respectively. The average scores in cardio vascular system problems were $4.42,4.44,4.46$ and 4.46 in groups A, B, C and D respectively. The possible score was between zero and sixteen. The average scores on urinary problems were found to be $11.30,11.38,11.34$ and 11.38 in groups A, B, C, and D respectively. The possible score was between zero and 26 . The average scores on gastro intestinal problems were found to be 13.5 in all the four groups. The average scores on integumentary problems were found to be 3.22 in all four groups. The average scores on sleep problems were found to be $5.76,5.78,5.80$ and 5.82 in group A, B, C \& D respectively.

\subsection{Section 4: Description of psychosocial problems among institutionalized elderly in all four}

As shown in Table 5 the average scores on loneliness related problems were found to be 5.96, 5.98, 6.00 and 6.02 in groups A, B, C and D
Table - 5

Mean and standard deviation of psychosocial problems before intervention ( $\mathrm{n}=$ 200).

\begin{tabular}{lllll}
\hline Groups & Mean & $\begin{array}{l}\text { Standard } \\
\text { Deviation }\end{array}$ & $\begin{array}{l}\text { ANOVA 'F' } \\
\text { Value }\end{array}$ & P Value \\
\hline Control & 38.18 & 7.52 & 0.020 & 0.996 \\
Laughter therapy & 38.30 & 7.42 & & (NS) \\
$\begin{array}{c}\text { Nurse Led } \\
\quad \text { Intervention }\end{array}$ & 38.38 & 7.52 & & \\
$\begin{array}{c}\text { Combined } \\
\text { intervention }\end{array}$ & 38.54 & 7.55 & & \\
\hline
\end{tabular}

respectively. The average scores on social isolation related problems were found to be $4.48,4.52,4.56$ and 4.58 in groups A, B, C and D respectively. The average scores on anxiety related problems were found to be 4.96, 4.98, 5.00 and 5.02 in groups A, B, C and D respectively. The average scores on problems related to neglect by family members were 7.74, 7.76, 7.78 and 7.80 in groups A, B, C and D respectively. The average scores on lack of self confidence were found to be $3.86,3.84$, $3.82,3.82$ in groups A, B, C \& D respectively. The maximum score is between zero to four. The average scores related to memory loss were 2.86, 2.88, 2.86 and 2.92 in groups A, B, C and D respectively.

\subsection{Section 6: Effect of laughter therapy on BADL deficit, physical and psychosocial problems among elderly}

In the posttest score all the subjects in the laughter Therapy group had improvement in BADL, physical and psychosocial problems. After laughter therapy the BADL deficit significantly decreased from 5.46 to 4.42 in interventional group B. After laugher therapy the mean score of physical problems reduced from 50.04 to 36.56 and psychosocial problems from 34.36 to 26.04 .

6.6. Section 7: Effectiveness of Nurse Led Intervention on BADL deficit, physical and psychosocial problems among elderly

In the posttest score all the subjects in the Nurse Led Intervention group had improvement in BADL, physical and psychosocial problems. After Nurse Led Intervention BADL deficit significantly decreased from 5.34 to 3.72 in interventional group C. After Nurse Led Intervention the mean score of physical problems reduced from 50.08 to 30.82 and 
psychosocial problems from 38.38 to 28.80 .

6.7. Section 8:Combined effect of laughter therapy and Nurse Led Intervention on BADL deficit, physical and psychosocial problems among elderly

In the posttest score all the subjects in the combined interventional group had improvement in BADL, physical and psychosocial problems. After combined intervention, the BADL deficit decreased from 5.82 to 2.30 in interventional group D. After Combined intervention the mean score of physical problems reduced from 50.18 to 27.38 and psychosocial problems from 38.54 to 21.12 .

\subsection{Section 9: Comparison of posttest mean level of BADL deficit among} four groups

As shown in Fig. 1 the mean level of BADL deficit during posttest in all the four groups. Means scores were 5.40, 4.42, 3.72 and 2.30 in group A, B, C and D respectively. One way ANOVA test was applied to compare the above four mean levels. The significant ' $\mathrm{P}$ ' value inferred that all the 4 group's mean levels were different. To find out which of the group differed, LSD multiple comparison test had been applied. The result showed that group D is better than all the other 3 groups. Group $C$ is better than the group B and A, and group B is better than group A. From the results it had been concluded that laughter therapy and Nurse Led Intervention are effective but combined intervention is more effective than the other 2 intervention in reducing BADL deficit among the institutionalized elderly. Also Nurse Led Intervention is more effective than laughter therapy in reducing the BADL deficit.

\subsection{Section 10: Comparison of posttest mean level of physical problems among four groups}

As per Fig. 2 the mean level of physical problems in posttest in all the four groups. They were 50.08, 36.56, 30.82 and 27.38 in group A, B, C and $D$ respectively with the standard deviation of 8.06, 5.96, 6.24 and 6.66. One way ANOVA test was applied to compare the above four mean levels. The significant ' $\mathrm{P}$ ' value inferred that all the 4 group's mean levels were different. At the end of the posttest after the intervention to find out which of the group differed, LSD multiple comparison test had been applied and the result showed that group $\mathrm{D}$ is better than all the other 3 groups. Group C is better than the group B and A, and group B is better than group A. From the results it had been concluded that

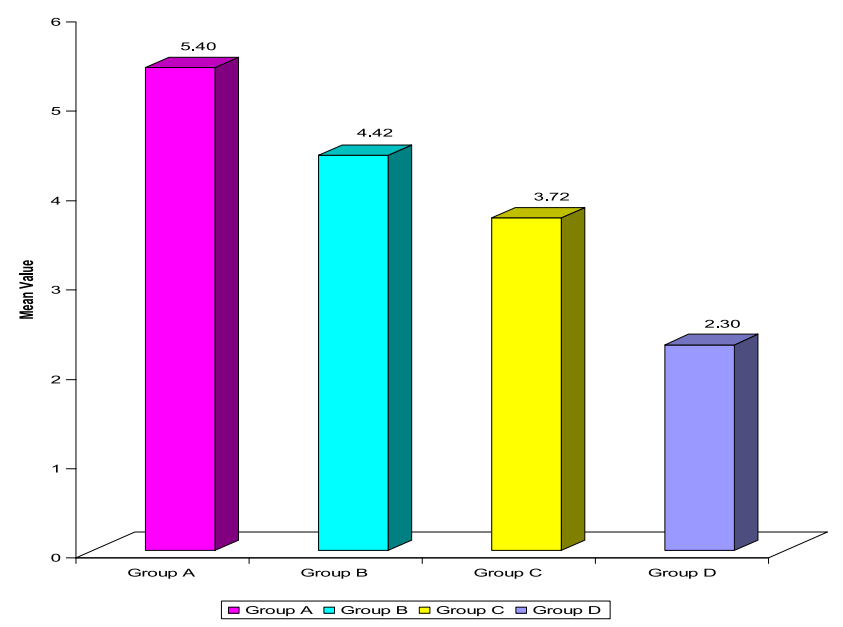

Fig. 1. Bar graph showing Comparison of Posttest Mean Level of BADL Deficit Among Four Groups $(\mathrm{n}=200)$.

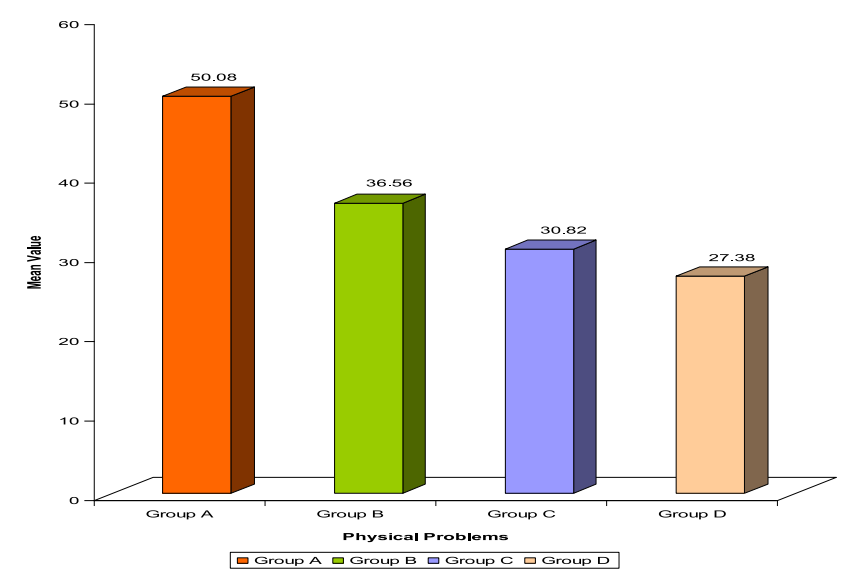

Fig. 2. Bar graph showing Comparison of Posttest Mean Level of physical problems among Four Groups $(\mathrm{n}=200)$.

laughter therapy and Nurse Led Intervention are effective but combined intervention is more effective than the other 2 intervention in reducing the physical problems. Also Nurse Led Intervention is more effective than laughter therapy in reducing the physical problems.

\subsection{Section 11: Comparison of posttest mean level of psychosocial problems among four groups}

Fig. 3 shows mean level of psychosocial problems in posttest in all the four groups. They were 38.54, 26.04, 28.80 and 21.12 in group A, B, $\mathrm{C}$ and D respectively with the standard deviation 7.55, 5.94, 5.76 and 4.87. One way ANOVA test was applied to compare the above four mean levels. The significant ' $\mathrm{P}$ ' value inferred that all the 4 group's mean levels are different. At the end of the posttest after the intervention to find out which of the group differed, LSD multiple comparison test had been applied. The result showed that group $\mathrm{D}$ is better than all the other 3 groups. Group $B$ is better than the group $C$ and $A$, and group $C$ is better than group A.

\section{Discussion}

BADL deficit among the institutionalized elderly: From the data it was revealed that majority of the elderly were able to use the napkins and put on chappals. The prevalence of BADL deficit among the elderly were more in putting on dress (95\%), Tooth brushing $96 \%$, using spoon or hand for eating $(90 \%)$, drinking from glass $(75 \%)$, combing hair

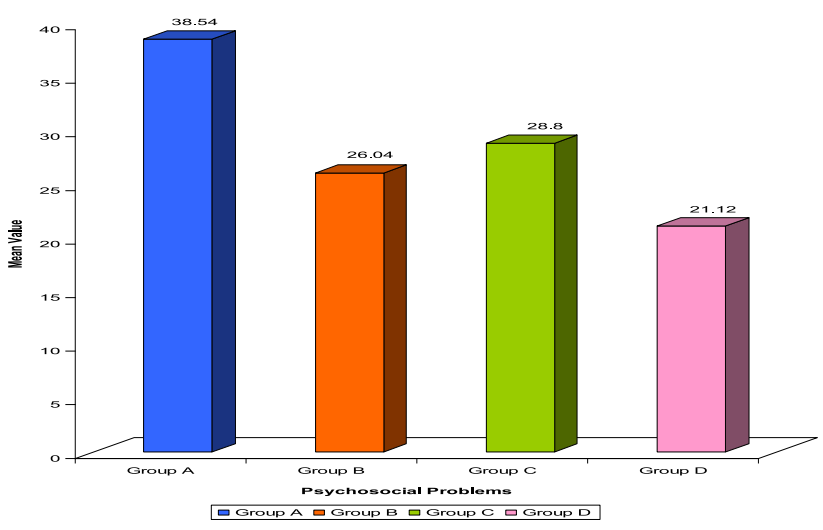

Fig. 3. Bar graph showing Comparison of Posttest Mean Level of psychosocial problems among Four Groups $(\mathrm{n}=200)$. 
(38\%), and less in face and hand washing (10\%), putting on chappals (8\%).

The present study finding is parallel to the findings of Priti, Kalaivani, Rai, Baridalyne, Nongkynrig and Gupta (2015) results revealed that among the 836 participants studied, the prevalence of functional disability was estimated to be $37 \%$. The prevalence was less among men (35.9\%) than women (38.8\%). The prevalence increased with age. It was concluded that functional disability is common among elderly persons in the rural area.

physical problems among elderly: Table 4 revealed that mean score on muscular system Problems was found to be 5.12, 5.16, 5.18 and 5.20 respectively for the groups $\mathrm{A}, \mathrm{B}, \mathrm{C}$ and $\mathrm{D}$ respectively. The average score on central nervous system problems was found to be 1.74 in all the four groups. The average score on respiratory system physical problems were $4.8,4.82,4.84$ and 4.86 respectively in groups A, B, C and D respectively. The average score on cardio vascular system problems were 4.42, 4.44, 4.46 and 4.46 in groups A, B, C and D respectively. The average score on urinary problems were found to be 11.30, 11.38, 11.34 and 11.38 in groups A, B, C, and D respectively. The average score on gastro intestinal problems were found to be 13.5 in all the four groups. The average score on integumentary problems were found to be 3.22 in all four groups. The average score on sleep problems were found to be $5.76,5.78,5.80$ and 5.82 in groups A, B, C \& D respectively. Statistical analysis revealed that the physical problem mean score was similar in all four groups.

The present study finding is similar to the findings of Anitha, Manjula and Jose (2014) found that $70.1 \%$ of the study sample had at least one disease. Most Common morbidities were musculoskeletal diseases, hypertension, diabetes, chronic obstructive pulmonary disease, coronary artery disease. Functional disabilities prevalent were visual, hearing, cognitive impairment, depression. Dependency increased with age.

The present study finding is in line to the findings of Kamble, Ghodke, Dhumale, Avchat and Goyal ${ }^{5}$ conducted a cross sectional study to assess the health status of elderly persons in India. Results revealed that commonest morbidity observed among the elderly people was depression (31.4\%) followed by musculoskeletal disorder (25.5\%), hypertension $(24.1 \%)$, gastrointestinal problems (11.5\%), diabetes mellitus (5.9\%), and neurological problems (4.7\%). This study has highlighted that the elderly suffer from multiple morbidities, which they often attribute to ageing. It requires the strengthening of geriatric health care services in accordance with the common existing problems in the community.

psychosocial problems among elderly: The average score in terms of depressive symptoms were 8.32, 8.34, 8.36 and 8.38 in groups A, B, C and $\mathrm{D}$ respectively. The average scores on loneliness related problems were found to be 5.96, 5.98, 6.00 and 6.02 in groups A, B, C and D respectively. The average score on social isolation related problems were found to be 4.48, 4.52, 4.56 and 4.58 in groups A, B, C and D respectively. The average scores on anxiety related problems were found to be $4.96,4.98,5.00$ and 5.02 in groups A, B, C and D respectively. The average scores on problems related to neglect by family members were 7.74, 7.76, 7.78 and 7.80 in groups A, B, C and D respectively. The average scores on lack of confidence were $3.86,3.84,3.82$ and 3.82 in group $\mathrm{A}, \mathrm{B}, \mathrm{C}$ and $\mathrm{D}$ respectively. The average problems related to memory loss were 2.86, 2.88, 2.86 and 2.92 in groups A, B, C and D respectively.

The findings were supported by the survey undertaken by a non government organization and Help Age India, conducted by Chopra ${ }^{6}$; has pointed a grim picture as far as lives of senior citizens were concerned. The survey was done among 500 senior citizens in Delhi and Mumbai and found that $12 \%$ said "no one cared whether they existed or not", $13 \%$ feel "trapped within their homes", $21 \%$ feel "more or less alone and socialize rarely including with their children". The study also revealed that $26 \%$ became lonely after retirement, $41 \%$ began to feel lonely after their spouse passed away and $33 \%$ said they were left alone after their children moved away. Fifty percentage of loneliness is related to age and $88 \%$ loneliness can lead to ailments. Sixty-six percentage of older persons living alone are lonely, $12 \%$ said those in nuclear families are lonely and $8 \%$ said they are lonely even in joint families.

\subsection{Effect of laughter therapy on BADL deficit, physical and psychosocial problems among elderly}

In the posttest score all the subjects in the laughter Therapy group had improvement in BADL, physical and psychosocial problems. After laughter therapy the BADL deficit significantly decreased from 5.46 to 4.42 in interventional group B. After laugher therapy the mean score of physical problems reduced from 50.04 to 36.56 and psychosocial problems from 34.36 to 26.04 .

It is supported by the study conducted by Maheswar, Shitok and Maya ${ }^{7}$ regarding laughter therapy and geriatric health. The study findings revealed that laughter therapy had significant role in geriatric health and prevention of diseases.

Fariba, Zahra, Iran and Farkhondeh (2015) which assessed the effects of laughter therapy on general health of elderly. Study results found a statistically significant correlation between laughter therapy programme and factors such as general health $(\mathrm{P}<0.001)$, somatic symptoms $(\mathrm{P}<0.001)$, insomnia and anxiety $(\mathrm{P}<0.001)$. Study concluded that laughter therapy can improve general health and its subscales in elderly people.

Hae and Chang ${ }^{8}$ did a study to investigate the effect of laughter therapy in depression, cognitive function, quality of life and sleep of elderly in the communities. After laughter therapy Geriatric Depression Scale (GDS) score were reduced from $7.98 \pm 3.58$ to $6.94 \pm 3.19$, the Mini Mental Status Examination (MMSE) score from $23.81 \pm 3.90$ to $24.63 \pm 3.53$, insomnia severity index from $8.00 \pm 6.29$ to $7.58 \pm 5.38$. Study results showed that there was a positive effect on depression, insomnia and sleep qualities in the elderly.

\subsection{Effectiveness of Nurse Led Intervention on BADL deficit, physical and psychosocial problems among elderly}

In the posttest score all the subjects in the Nurse Led Intervention group had improvement in BADL, physical and psychosocial problems. After Nurse Led Intervention BADL deficit significantly decreased from 5.34 to 3.72 in interventional group C. After Nurse Led Intervention the mean score of physical problems reduced from 50.08 to 30.82 and psychosocial problems from 38.38 to 28.80 .

Study findings were supported by Su and Shu (2007) conducted a programme on Self Care Self Efficacy Enhancement Programme (SCSEEP) on BADL deficit among Chinese elderly. Study results revealed that basic activities of daily living performance improved significantly in treatment group residents. Many Chinese elders are placed in nursing homes in the United States; thus, the SCSEEP may also be used as a theory-based caring model to improve self-care performance in Chinese Americans.

Nagpal (1995), who conducted an exploratory study of the self care ability and subjective well being of the elderly in institutional and family settings. Data was collected from 60 elderly each from both the settings using structured interview schedule. The findings of the empirical study of the elderly individuals (mean age $71.8 \mathrm{yrs}$ ) conducted by the author indicated that there is high potential among the elderly for self care and that the level of self care ability is related to the background of the elderly. The elderly have high self care abilities which, when supported, will add life to their years rather than years to life.

\subsection{Combined effect of laughter therapy and Nurse Led Intervention on $B A D L$ deficit, physical and psychosocial problems among elderly}

In the posttest score all the subjects in the combined interventional group had improvement in BADL, physical and psychosocial problems. After combined intervention, the BADL deficit decreased from 5.82 to 
2.30 in interventional group D. After Combined intervention the mean score of physical problems reduced from 50.18 to 27.38 and psychosocial problems from 38.54 to 21.12 .

Anna, Johana and Krishnan (2011) assessed the effectiveness of psychosocial intervention for the promotion of mental health and prevention of depression among elder adults. Study groups were divided into physical exercise, skill training, reminiscence, social activities, group support and multi component intervention. Overall psychosocial intervention had a positive effect on quality of life and positive mental health.

\subsection{Comparison of posttest mean level of BADL Deficit Among Four Groups}

The mean level of BADL deficit during posttest in all the four groups. Means scores were 5.40, 4.42, 3.72 and 2.30 in group A, B, C and D respectively. One way ANOVA test was applied to compare the above four mean levels. The significant ' $P$ ' value inferred that all the 4 group's mean levels were different. To find out which of the group differed, LSD multiple comparison test had been applied. The result showed that group $D$ is better than all the other 3 groups. Group $C$ is better than the group B and A, and group B is better than group A. From the results it had been concluded that laughter therapy and Nurse Led Intervention are effective but combined intervention is more effective than the other 2 intervention in reducing BADL deficit among the institutionalized elderly. Also Nurse Led Intervention is more effective than laughter therapy in reducing the BADL deficit.

Forsman and Nordmyr ${ }^{9}$ assessed the effectiveness of psychosocial interventions for the promotion of mental health and prevention of depression among elder adults. Study groups were divided into physical exercise, skill training, reminiscence, social activities, group support and multi component interventions. Overall combined psychosocial interventions had a positive effect on quality of life and positive mental health.

\subsection{Comparison of the mean level of physical problems among institutionalized elderly in posttest in all the four groups}

The mean level of physical problems in posttest in all the four groups. They were 50.08, 36.56, 30.82 and 27.38 in group A, B, C and D respectively with the standard deviation of 8.06, 5.96, 6.24 and 6.66 . One way ANOVA test was applied to compare the above four mean levels. The significant ' $\mathrm{P}$ ' value inferred that all the 4 group's mean levels were different. At the end of the posttest after the intervention to find out which of the group differed, LSD multiple comparison test had been applied and the result showed that group $\mathrm{D}$ is better than all the other 3 groups. Group $C$ is better than the group B and A, and group B is better than group A. From the results it had been concluded that laughter therapy and Nurse Led Intervention are effective but combined intervention is more effective than the other 2 intervention in reducing the physical problems. Also Nurse Led Intervention is more effective than laughter therapy in reducing the physical problems.

\subsection{Comparison of the mean level of psychosocial problems among institutionalized elderly posttest in all the groups}

Mean level of psychosocial problems in posttest in all the four groups. They were 38.54, 26.04, 28.80 and 21.12 in group A, B, C and D respectively with the standard deviation $7.55,5.94,5.76$ and 4.87. One way ANOVA test was applied to compare the above four mean levels. The significant ' $\mathrm{P}$ ' value inferred that all the 4 group's mean levels are different. At the end of the posttest after the intervention to find out which of the group differed, LSD multiple comparison test had been applied. The result showed that group D is better than all the other 3 groups. Group B is better than the group C and A, and group C is better than group $\mathrm{A}$.

From the results it had been concluded that laughter therapy and Nurse Led Intervention are effective but combined intervention is more effective than the other two intervention in reducing the psychosocial problems. Also laughter therapy is more effective than Nurse Led Intervention in reducing the psychosocial problems.

\section{Conclusion}

People worldwide are living longer. By 2050, the world's population aged 60 years and older is expected to total 2 billion, up from 900 million in 2015. Today, 125 million people are aged 80 years or older. There is no 'typical' older person. Some 80 -year-olds have physical and mental capacities similar to many 20 -year-olds. Other people experience significant declines in physical and mental capacities at much younger ages. A comprehensive public health response must address this wide range of older people's experiences and needs. Health systems need to be better organized around older people's needs and preferences, designed to enhance older peoples intrinsic capacity, and integrated across settings and care providers. Actions in this area are closely aligned with other work across the Organization to strengthen universal health care and people-centred and integrated health services. Systems of long-term care are needed in all countries to meet the needs of older people. This requires developing, sometimes from nothing, governance systems, infrastructure and workforce capacity. WHO's work on long-term care (including palliative care) aligns closely with efforts to enhance universal health coverage, address non-communicable diseases, and develop people-centred and integrated health services.

\section{Limitations}

Nil.

\section{Funding}

This research did not receive any specific grant from funding agencies.

\section{Declaration of competing interest}

Authors declare that there is no conflict of interest.

\section{Acknowledgement}

None.

\section{References}

1 Sundar. Ageing and stress. Br Med J. 2009;26(2):11-18.

2 World Health Organization. Active Ageing: A Policy Framework. 2003, $2^{\text {nd }}$ November 2010.

3 Rakesh S, Babita S, Beulah SL, Varidmala J. Psychosocial problems: an issues among the elderly in. Int J Health Sci Res. 2013;3(6):48-53.

4 Yun, Tsai, Yeh. Prevalence and risk factors for depressive symptoms among community dwelling elders in Taiwan. Int J Geriatr Psychiatr. 2004;20(11):1097-1102.

5 Kamble SV, Ghodke YD, Dhumale GB, Avchat SS, Goyal RC. Health status of elderly person in rural area of India. Indian Med Gaz. 2012;12(8):295-299.

6 Chopra D. Geriatric health in India. Indian J Community Med. 2007;33(2):214-218.

7 Maheswar S, Maya P. Laughter is the most effective geriatric medicine. International Inter disciplinary Research Journal. 2012;2(4):71-78.

8 Hae and Chang. Effects of laughter therapy on depression, cognition and sleep among the community-dwelling elderly. International Journal of Geriatrics and Gerontology. 2011;11(3):267-274.

9 Forsman K, Nordmyr J. Psychosocial interventions for the promotion of mental health and the prevention of depression among older adults. Journal of Health Promotion International. 2011;26(1):85-107. 